\title{
LA RESURRECCIÓN DIGITAL DE LOS MUERTOS: TRADUCCIÓN Y CRÍTICA DE UN HITO DE LA LITERATURA DIGITAL
}

\author{
Agustin Federico Berti \\ Susana Romano Sued ${ }^{*}$
}

\begin{abstract}
RESUMEN: El artículo propone una lectura crítica y un modelo de traducción para obras experimentales en el contexto de la literatura digital. En primer lugar, presentamos el poema autoencriptable de 1992 "Agrippa (A Book of the Dead)" ["Agrippa (Un libro de los Muertos)"] de William Gibson, que formaba parte del objeto-libro Agrippa ( $A$ Book of the Dead), una obra en colaboración del propio Gibson, el editor Kevin Begos y el artista plástico Dennis Ashbaugh. En segundo lugar, contextualizamos la emergencia de la obra y su impacto. En la tercera sección, presentamos las traducciones existentes del poema y oferecemos uma propuesta metodológica para la traducción. En función de nuestra propuesta de traducción, se presenta un panorama de la crítica sobre la obra y de la importancia de la leitura crítica y um fragmento de nuestra versión en español. Finalmente discutimos la importancia de la obra en el contexto de la digitalización de la cultura.
\end{abstract}

PALABRAS-CLAVE: Agrippa. Traducción. Poesía experimental. Literatura digital. William Gibson.

\section{La traducción y las obras digitales: textos y códigos}

La traducción es un problema que atraviesa la historia de la literatura. Cuando la literatura se recodifica en nuevas tecnologías de representación, el traductor se enfrenta a nuevos desafíos que se agregan a los existentes. Este trabajo discute los procedimientos para la traducción de un hito de la literatura digital, Agrippa ( $A$ Book of the Dead) a partir del modelo propuesto en La diáspora de la escritura y "Poesía de experimentación: traducción del poema visual "Jetzt" de Max Bense al castellano" (ROMANO SUED, 1995; 2008). En el contexto de la literatura digital o e-literature, siguiendo la clasificación propuesta por Hayles (2007), encontramos que el problema de la traducción se superpone el problema de la digitalización, que implica una operación de codificación binaria. Asimismo, cobra renovada

\footnotetext{
UNCor/Conicet. Imeio: agustin.berti@gmail.com.

UNCor/Conicet. Imeio: susana.romano@gmail.com.
}

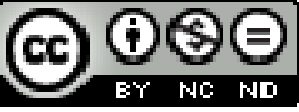

Texto Digital, Florianópolis, v. 8, n. 2, p. 19-52, jul./dez. 2012. ISSNe: 1807-9288 
relevancia la dimensión artefactual de las obras. Por su propia inscripción histórica y material, las obras de literatura digital se inscriben necesariamente en una genealogía técnica regida por la dinámica de la obsolescencia (FERRER, 2005). Estas obras "funcionan" en determinados contextos técnicos y entornos de software y una traducción crítica completa supondría, al menos, la emulación de ese entorno ya que en las mismas el texto verbal es sólo uno de los elementos que hacen a la totalidad de la obra.

De este modo, una traducción crítica fidedigna supone la reproducción íntegra del "texto original", que para el caso de "Agrippa" es imposible en el espacio acotado del presente artículo, una lectura de la obra y sus contextos críticos, una aproximación al mismo en sus distintos planos $y / 0$ niveles (a. fono $y$ morfosintáctico; b. semántico; c. estructura discursiva), así como la reconstrucción de los aspectos intermediales, intertextuales e intercódigo. En este punto cabe señalar que lo metapoético y la necesaria heteronomía de las obras digitales por su evidente inscripción técnica juegan un papel fundamental y pertinente en el dominio de la crítica como "invariantes de traducción" (ROMANO SUED, 1995), es decir determinar el gesto poético global configurado a partir de la articulación de aquellos elementos básicos de la estructura dispuestos jerárquicamente.

De lo obtenido de la aproximación analítico-interpretativa, en la fase segunda, o interlingual e intermedial, se construye un conjunto de opciones y lo que denominamos "escala de invariantes", con los aspectos dominantes de cada dimensión. Esto conduce a la reconstrucción del "gesto poético global". Con "escala" y "gesto", se escribe el "texto de llegada" (ROMANO SUED, 1995).

En la fase crítica, se agregan los aspectos que se desprenden de la condición de nuevo texto en la lengua y en el sistema poético de llegada, su inserción en el o los géneros y lenguajes en que se inscribe, los instrumentos categoriales pluridisciplinares con que ha de analizarse este nuevo "objeto estético" y la relación que se genera con otras versiones disponibles. 


\section{Breve genealogía de un acontecimiento artístico: aproximación a la génesis del texto de partida}

En diciembre de 1992 apareció ${ }^{1}$ Agrippa (A Book of the Dead) [Agrippa (Un Libro de los Muertos)], un libro-objeto que marcaría un módico hito en la relación artetecnología y que se convertiría en pieza anticipadora en el incipiente debate sobre el futuro de los objetos que entendemos como libros (los códex, para ser más precisos) ante el creciente avance de las tecnologías digitales. El proyecto editorial, propiamente colaborativo, fue llevado a cabo por Kevin Begos, un editor especializado en libros-objeto y libros de arte, e incluía aguafuertes del artista plástico Dennis Ashbaugh y un texto del escritor William Gibson. Asimismo, la obra contiene un poema autobiográfico de William Gibson, famoso por su obra narrativa dentro un género como la ciencia ficción (sumamente identificado a la industria cultural), paradójicamente de culto y masivo. Las aguafuertes de Ashbaugh insertan la obra en el campo de las artes visuales, otorgando a la obra su carácter fuertemente intermedial, pero también dotándola de valor en el mercado del arte, potenciado esto último por su presentación en el ámbito del arte contemporáneo de Nueva York.

Agrippa constituye una obra radicalmente atípica en la que se revelan problemáticas centrales concernientes al arte y a la literatura en el contexto de la digitalización. Se trata de un texto relativamente desconocido que interpela fuertemente a la crítica y la reflexión y requiere de perspectivas multidisciplinares para su análisis. En su factura, la obra imbrica soporte, texto literario, imagen artística y código binario, comportando un signo complejo y multidimensional. En su singularidad, en tanto obra de arte intrusiva, Agrippa excedió la convención del "texto literario" y alcanzó la dimensión en acto estético y político precisamente en el momento de la conformación de un nuevo sensorium marcado e inscripto por la

\footnotetext{
${ }^{1}$ Optamos por la idea de "aparición" antes que la de "publicación" o "lanzamiento" ya que la fecha de publicación no da cuenta de la compleja historia editorial y posterior circulación de la obra que será discutida en extenso en los próximos capítulos.
} 
creciente mediatización tecnológica, el fetichismo de la mercancía, y la expansión de la globalización.

Las obras producidas en este periodo, por sus modos peculiares de recepción y circulación vuelven a poner en discusión problemas que habían sido invisibilizados por siglos de hábito. Uno de los problemas más relevantes, el que da origen al mito del fin del libro es el del "soporte". El concepto supone una neutralidad en la técnica y por ello se asume que las obras serían entidades ideales que pueden ser actualizadas en outputs materiales diversos sin perder sus cualidades "esenciales". De este problema se deriva un segundo problema, el del dispositivo, que en el contexto de las tecnologías digitales aparece como un mero actualizador de "contenidos", y que contribuye a borrar el rol del segundo término implícito, el del "continente". La dinámica de los contenidos puros que se establece a partir de la digitalización se desarrolla en función de la reproductibilidad teóricamente idéntica que permite la codificación y posterior replicación digital. Este fenómeno exacerba la reproductibilidad técnica, y confirma el fenómeno señalado por Benjamin: la primacía del valor de exhibición sobre el valor de culto (BENJAMIN, 1989).

Agrippa constituía una provocación al proponerse como pieza de lectura única, ya que en su misma producción estaba planeado el impedimento para que su relectura fuera imposible: sería posible leer el texto y contemplar las ilustraciones una sola vez, demoliendo el principio de conservación que hace de la escritura el registro de la memoria, y de los libros sus soportes privilegiados. $Y$ no casualmente el tópico por excelencia de la obra lo conformaban la memoria y los dispositivos técnicos.

Más allá de su éxito relativo, uno de los rasgos distintivos del proyecto de Agrippa lo determina la pretensión de generar una experiencia única e intransferible, "aurática" en términos benjamineanos, mediante la combinación de tecnologías digitales -que, en teoría, garantizan una reproductibilidad técnica infinita y sin degradación- con tecnologías de reproducción analógica como la imprenta y el 
grabado. De modo que la obra cuestionaba por una parte, la idea de la pervivencia de los soportes analógicos, de naturaleza material por excelencia; y por otra parte, cuestionaba también la de los digitales, a los que la idealización de la técnica les confiere la ilusión de una mayor conservación por la transcendencia de lo material en lo que se ha denominado "ideología medial" (KIRSCHENBAUM, 2008, pp.36-45).

Durante una década Agrippa fue una suerte de Cardenio de Shakespeare de la literatura digital: apenas un rumor y algunas noticias sobre una obra que no se sabía si era apócrifa, una humorada o directamente un proyecto abandonado. Desde sus orígenes el proyecto apuntaba a diversos públicos (y a sus modos de circulación específicos): el público lector de ciencia ficción, el coleccionista de arte, el coleccionista de libros, los museos e instituciones de preservación cultural, la subcultura hacker. La anomalía es el estatuto dominante de la obra: el libro se compone de una impresión ilegible por ser un código de ADN, imágenes que se borran al contacto con el dedo y un texto digital efímero que se autoencriptaba permitiendo una única lectura. Agrippa ofrece así un ejemplo privilegiado para discutir el rol del arte y la literatura en relación a la técnica y la industria cultural en los orígenes de la digitalización y la emergencia de una doble naturaleza material y digital propia de las obras artísticas en el presente.

Los distintos eventos relacionados a la circulación de Agrippa (su presentación en la America's Society de Nueva York, el encriptado, la prohibición gubernamental de vender el libro fuera de los Estados Unidos por la tecnología utilizada, la filtración del poema encriptable, su difusión en los BBS $^{2}$ de la época, la aparición de "memes"3 y la leyenda gestada en torno al objeto libro Agrippa) hacen confluir en una única obra distintos tipos de digitalización (por escaneo y por tipeo) y las diversas, y por momentos contradictorias, implicaciones de los mismos.

\footnotetext{
${ }^{2}$ El Bulletin Board System (Sistema de Tablón de Anuncios) o BBS es un software para redes de computadoras que permite a los usuarios conectarse al sistema para descargar software y datos, leer noticias, intercambiar mensajes con otros usuarios, utilizar de juegos en línea, leer boletines, etc. Hoy está casi en desuso, y fue reemplazado por los blogs y las redes sociales.

${ }^{3}$ Los "memes digitales" son variaciones (generalmente paródicas) a partir de un textos o imágenes, tanto digitales como digitalizados. Los "memes" de Agrippa han sucitado discusión académica (KIRSCHENBAUM, 2008; BERTI, 2010)
} 
En el presente trabajo ofrecemos una interpretación del poema "Agrippa", un modelo para una traducción crítica de esta obra y obras similares, y una discusión con los trabajos académicos que han abordado la obra.

\section{Traducciones de "Agrippa” y discusión metodológica}

Existen muy pocas traducciones de "Agrippa", todas al castellano. Se trata de traducciones literales de aficionados que parten del texto on-line sin mayores contextualizaciones. Hemos identificado cuatro: la de "Saurio" en La idea fija. Revista bastante literaria, que está basada en la versión del sitio de Gibson (GIBSON, 2004), la de "Da5id", subida al sitio Scribd.com por "api_user_11797_Francisco Lorin Colorado" (GIBSON, 2008b) y un fragmento (vv. 1-33) en el blog La tumba del pardo posteado por "immorfo" (GIBSON, 2008a). Como es la norma en este tipo de publicaciones digitales los datos bibliográficos son bastante imprecisos. Asimismo hay indicación en internet de una traducción realizada por Sergio Martínez Mourelle, publicada en la revista de ciencia-ficción española $A d A s t r a{ }^{4}$. En lo que respecta a la nacionalidad de los traductores hemos podido determinar que "Saurio" es argentino, "immorfo" es mexicano y Martínez Mourelle es español.

En el marco del proyecto de investigación Metaliteratura y metaficcionalidad. Modelos literarios y críticos en una constelación de autores contemporáneos llevamos a cabo una traducción crítica del poema "Agrippa" que estaba en el diskette contenido dentro del objeto-libro Agrippa, siguiendo los saltos de líneas y la representación visual del texto tal como se reproducía al ejecutar el archivo. Por su extensión solo reproduciremos algunos fragmentos. En las notas al pie de la traducción, se brindan comentarios tendientes a aclarar algunas de las referencias culturales sumamente específicas, que, como retomaremos luego, son un rasgo constitutivo de la escritura gibsoniana, más cercana a lo que

\footnotetext{
${ }^{4}$ Ad Astra es una revista de circulación acotada a la península ibérica. No hemos podido conseguir el ejemplar en donde se publicó la traducción de "Agrippa". Por otra parte cabe señalar que no es una publicación de referencia en el género como El Péndulo o Minotauro, publicadas por la editorial homónima que, además, es la poseedora de los derechos de la obra de Gibson.
}

Texto Digital, Florianópolis, v. 8, n. 2, p. 19-52, jul./dez. 2012. ISSNe: 1807-9288 
Frederic Jameson, específicamente para describir la escritura de Gibson, ha definido como "nominalismo postmoderno" (JAMESON, 2003), que al cyberpunk con el que lo han identificado otros críticos (LIU, 2004, pp.339-348; SCHWENGER, 1994, pp. 61-70)5. Optamos por mantener la agramaticalidad aparente del uso de comas y puntos presente en la versión original aunque esto entorpezca un poco la comprensión. En casos donde en español puede omitirse el sujeto pronominal lo hemos mantenido cuando éste hace referencia a la figura del padre para evitar ambigüedades que no aparecen en el original. Por último, cabe señalar que esta versión no se corresponde exactamente con aquellas que circularon en los BBS tras el crackeo en $1992^{6}$ ni, sorprendentemente con la que su autor presenta en su sitio web "with the correct line-breaks, etc."7. (GIBSON, 2002) $)^{8}$.

Atendiendo a la importancia de los aspectos experimentales y visuales que hacen al poema, tomamos en cuenta para nuestra traducción algunas observaciones propuestas para la traducción del poema visual “Jeztz!" de Max Bense:

La creación y captación procesual y múltiple de los poemas visuales entrañan en sí mismas operaciones que podemos llamar de estereocepción, y actividad retroalimentada entre creadores y receptores. En estas creaciones cambia la percepción y cambia la recepción como su correlato; es decir, se modifica la función del receptor y su relación con la obra, el arte y el artista. El receptor se ve exigido en una actitud activa, para hacer lugar a una experiencia, la experiencia estética. Se produce efectivamente entonces la condición procesual de la creación-recepción del poema.

\footnotetext{
${ }^{5}$ El cyberpunk es el subgénero de la ciencia-ficción en el que se suele inscribir a Gibson.

${ }^{6}$ El poema contenido en el objeto libro Agrippa se autoencriptaba luego de la primera ejecución. El lanzamiento de la obra se realizó en el evento denominado "The transmission" [La transimión] el 9 de diciembre. Al día siguiente, el poema, "crackeado" apareció on-line en el BBS MindVox. A diferencia de una obra como afternoon, que circulaba básicamente en diskette (y luego en CDRom), Agrippa apareció en una época en la que ya comenzaba a insinuarse la circulación digital a través de redes. Para una discusión sobre las particularidades de Agrippa véanse los trabajos ya mencionados de Kirschenbaum (2008) y Berti (2010), así como The Agrippa Files (LIU et al. s. f.), , el sitio web académico dedicado a la obra.

7 "con los saltos de línea correctos, etc".

${ }^{8}$ Kirschenbaum señala la paradoja de que la versión que se ofrece en el sitio web de Gibson presenta erratas que no estaban presentes en las primeras versiones filtradas (2008, p.239). Esto no hace más que avalar su tesis de que "Agrippa" es uno de los mejores ejemplos de preservación digital por propagación con pérdida.
} 
Es posible afirmar igualmente que en la factura misma de poemas experimentales, concretos, visuales, hay también operaciones de traducción. Una traducción que tiene lugar en el interior del sistema lingüístico-visual de partida. Esta complejidad constituye un reto para el vertido de estos textos, que llamaremos textosimagen, a otros sistemas lingüísticovisuales. Si la creación de estas obras es el resultado de complejos procesos que a su vez demandan la actividad multisensorial e intelectiva de sus receptores primarios, su lectura, interpretación y vertido a otros sistemas lingüísticos y culturales diversifican y profundizan en muchos casos tal complejidad. (ROMANO SUED, 2008, p. 2)

El grado de "textoimagen" de "Agrippa" es relativamente bajo, en tanto su mayor peculiaridad es el movimiento del texto desde abajo hacia arriba de la pantalla similar al scrolling que hoy es la norma en la lectura de textos digitales. Su mayor complejidad visual es un escaneo del rótulo de un álbum (marca Kodak, modelo Agrippa) original al comienzo del poema. Debemos asimismo tener en cuenta que la actitud activa para la experiencia estética señalada en el trabajo antes citado, en Agrippa se daba por la conciencia de la pérdida irremisible del poema una vez concluido el scrolling, imposible de detener una vez iniciado, y la especial predisposición que eso imponía en el lector al enfrentarse a la obra. Una traducción "completa" y fidedigna, requeriría el código sin compilar del cual se generó el programa ejecutable "Agrippa (a book of the dead)" que está en los diskettes originales de Agrippa y junto con ello los dos recursos sonoros (el sonido del cierre de un obturador de cámara fotográfica y el de un disparo, que se encuentran en los archivos, "camera7.aiff" y "gunshot.aiff") así como el escaneo en blanco y negro "pict1.png" del rótulo de los álbumes Kodak Agrippa originales que también se reproducía en la esquina superior del objeto Agrippa y reemplazar en el código el texto en inglés por el traducido?

En función de lo expuesto, recomendamos fuertemente que para una primera lectura del texto se mire el archivo de video de 20 minutos de duración "AGRIPPA (A Book of the Dead)_ The Poem Running in Emulation (480p_H.264-AAC)" que es el registro de una ejecución del archivo tal como se preveía en el proyecto

\footnotetext{
${ }^{9}$ Estos archivos han sido puestos a disposición por el análisis de la imagen del disco de Agrippa realizado por François Grieu (2008) y el crackeo académico realizado por Freek Wiedijk (2011) incluidos en el acervo de The Agrippa Files (LIU et al., s. f.).
}

Texto Digital, Florianópolis, v. 8, n. 2, p. 19-52, jul./dez. 2012. ISSNe: 1807-9288 
Agrippa en 1992. Es necesario tener encendidos los parlantes para escuchar los sonidos incidentales ${ }^{10}$.

\section{El "mecanismo" de "Agrippa": estructura, análisis e interpretación del poema}

El poema "Agrippa (Un Libro de Los Muertos)" consiste de trescientos tres versos divididos en seis partes: I (vv. 1-97), II (vv. 98-144), III (vv. 145-181), IV (vv. 182217), V (vv. 218-262) y VI (vv. 263-303). En las secciones I, II y III el yo poético abre el álbum, y se describen las fotografías viejas que hay en él. El álbum de fotos es "el libro de los muertos", la familia paterna del padre de Gibson que murió cuando este era un niño. El álbum es descripto en su materialidad ("de papel corrugado" (v.9)) y su degradación física ("Negro y quemado por el tiempo." (v. 10), "sus férulas de metal carcomidas por el oxígeno" (v.15)). El paso del tiempo se asocia en la progresión de los versos a la degradación material que paradójicamente afecta a las imágenes fotográficas, supuestos momentos eternizados. La tensión entre la eternidad de la imagen fotografiada y la contingencia de la existencia material de la copia articula esta sección y las dos siguientes. La materialidad remite a la inevitable degradación material de los registros que justamente apuntan a evitar el olvido: la fotografía envejecida, los epígrafes manuscritos borrados ("Dentro de la tapa él grabó algo en granito tenue / ahora perdido / entonces su nombre" (vv. 17-19)). La remisión a la materialidad particular de los distintos objetos y productos técnicos también es recurrente: el "granito tenue" (v.17) del lápiz, la "fantasmal claridad Kodak" (v. 41) de las imágenes fotográficas, el "dulce y caliente hedor" (v. 31) de la sierra eléctrica. Como la madalena de Proust, la infancia está asociada a los olores de un entorno. Sólo que en este caso se trata de un entorno donde las máquinas, el "mecanismo" que articula iterativamente el poema, son el lugar sobre el que vuelve la memoria. Entendemos este recurso como una desidealización de la técnica, en la cual se diluye su connotación de futuro al presentarla como pasado

10 El video está disponible en <http://www.youtube.com/watch?v=41kZovcyHrU> y en $<$ http://agrippa.english.ucsb.edu/category/the-book-subcategories/the-poem-running-in-emulation $>$. 
sujeto a la degradación y al olvido. Este tono se ve acompañado por una progresión de la técnica que resalta el contraste entre un mundo rural y uno crecientemente urbano, que va de los "zapatos blancos de la ciudad" (v. 75) (que contrasta con la imagen del niño "aún con sombrero de paja" (v. 66)) a el "auto de paseo con techo de lona" (v. 78), del "elegante arco / de cemento" (vv.80-81) a "una demolición posterior" (v. 90) o del "Barco a vapor en el río Ohio" (v. 154) a "la ribera lejana / repleta de fábricas" (vv. 157-158).

Los versos "ALBUMS / CA. AGRIPPA / Solicite Hojas Extra / Por Letra y Nombre" (vv. 5-8) repiten el fragmento que se reproduce en la tapa del objeto libro (ver imágenes 33 y 34) y que es una reproducción de una parte del álbum marca Agrippa encontrado por Gibson cerca la fecha de inicio del proyecto Agrippa. El detalle menor apunta a la indicialidad inherente a un objeto indiscutiblemente aurático como lo es un álbum de fotografías familiares de comienzos de siglo cuyos negativos previsiblemente ya se han perdido. Lo aurático del objeto único también guarda una relación con la propia biografía del escritor y el valor de la mirada que devuelven esos retratos en cuyas écfrasis pueden rastrearse los ecos de los "incunables de la fotografía", como los califica Benjamin, y que son de una época en la que técnica y humanidad no estaban divorciadas, ya que la fotografía, en su estadio artesanal, podía ser incorporada a la tradición: "El rostro humano tenía a su alrededor un silencio en el que reposaba la vista. En una palabra: todas las posibilidades de este arte del retrato depende de que aún no se ha producido el contacto entre la actualidad y la fotografía" (BENJAMIN, 2004, p. 29).

La lectura benjamineana señala una época de "correspondencia" entre técnica y cultura. La época (entre 1917 y 1924) y el lugar en el que se tomaron las fotografías (un pueblo rural del sur de los Estados Unidos), en conjunción con el abaratamiento de las cámaras portátiles pequeñas, que propició la aparición de una práctica fotográfica amateur guarda similitudes con la época descrita por Benjamin. Esta práctica específica, en el contexto puntual de un espacio en tránsito entre una sociedad tradicional a una industrial, constituyó un momento 
especial que replica los aspectos de imbricación entre técnica y cultura que Benjamin detectaba en la fotografía de mediados del siglo XIX en fotógrafos como David Octavius Hill (BENJAMIN, 2004, pp. 28-35). La correspondencia entre técnica y cultura vuelve a aparecer en otros "mecanismos" como la sierra eléctrica que va dando forma a la madera, pero el desarrollo va modificando esa situación hasta transformarla en un tiempo perdido.

Las referencias a la modernización a lo largo del poema acentúan el extrañamiento y el contraste, la idea de atraso ante un progreso que se ve incluso en su ausencia como en el caso de "La calle principal" que "no está pavimentada" y la "luz eléctrica que "cuelga / de un cable flojo" (vv. 162-165). El agente de ese impulso modernizador es la figura del abuelo fascinado por los materiales modernos que perviven con el tiempo pero "sin encanto entre las extensiones / de dulces y desparejos ladrillos mohosos que conocieron las herraduras de los / caballos yanquis" (vv. 174-175). En estos versos puede verse la tensión entre el pasado acumulado sobre algunos materiales que van registrando en su decadencia el paso del tiempo frente a los modernos que se mantienen aparentemente inalterados pero desentonan con el espacio.

La tensión se vuelve a hacer presente en la contraposición entre los modernos Oldsmobile estacionados en la calle y el "piso del almacén de tablones de madera" (v.155). La dimensión social del progreso (y las tensiones que implica) también puede verse en la ironía sobre la ampliación del comedor de la estación de buses al tirar los baños para la gente de color cuando ya "no fue necesario" ( $v$. 234). La conquista de derechos civiles puede rastrearse en los cambios del edificio que pasa a albergar "una fría cueva de sueños fluorescente" (v. 238) pero donde aun persistían los miedos "de aquellos otros incalculables" (v. 241) torturados por la policía en esos baños.

La referencia es oblicua pero permite reconstruir el conservadurismo de un pueblo del sur rural de los Estados Unidos, donde hay un baño para negros, donde el sheriff controla que quien se baja del bus vuelva a subir y donde, se 
sugiere, algunos sufrían o no "según la ley creyera adecuado" (v. 245). La creciente red de caminos es así otro signo del progreso (y las reacciones que genera). Otra expresión del ubicuo "mecanismo" que también puede verse en los semáforos cuyos temporizadores se escuchan a una cuadra de distancia; "mecanismo" que resuena también en el gruñido de los camiones sobre la autopista. Finalmente, la estación es derribada y reemplazada por "una filial de una cadena" (v. 296). En estos versos, el yo poético ya está situado en un en el presente, en el distrito de Chiyoda-ku en Tokio donde un temporal hace bambolear los faroles. La diferencia radical estriba en que el yo poético es ya en completamente conciente del mecanismo que antes era intuido.

La repetición de la imagen de la luz eléctrica que el viento sacude sobre el cable flojo en Wheeling en 1921 "sugiriendo la dirección en la que podría caer en un vendaval" y los faroles que se bambolean en Tokio en el presente del poema, setenta años después (y en las antípodas de un pueblito rural y conservador) marcan una contraposición entre Tokio y Wheeling. La contraposición organizada a partir de la iteración del mecanismo constata una maduración sentimental del yo poético e impide hablar de un "tono elegíaco" (LIU, 2004), o mucho menos "apocalíptico" (SCHWENGER, 1994), sino de una plena conciencia de la matriz técnica del mundo pero "riéndose" (v. 303).

Por otra parte la contraposición cierra el círculo establecido entre dos objetos. El primero son los cortaplumas fabricados en Japón que eran uno de los objetos recordados de la infancia (asociados además al hábito infantil de comer sandías, típico del sur rural de los Estados Unidos). El segundo es el paraguas invertido en medio del temporal en Chiyoda-ku en ese mismo Japón, que antes era el incierto lugar de origen de las baratijas compradas en Wheeling. Es justamente ese Japón donde las lámparas que se bambolean, donde el "mecanismo" resulta gracioso (y no ominoso) al ser zarandeado por la naturaleza.

El "mecanismo" es la imagen que articula el poema. Aparece bajo formas diversas: el libro de fotografías, la cámara de fotos, la pistola, la red de 
semáforos, la ciudad, el alumbrado público. También el mecanismo se infiere en la red de caminos, en la oficina de leva, la oficina de migraciones (en suma, en el Estado). Sin embargo, no consideramos que en el poema el "mecanismo" aparezca en un sentido ominoso desde el momento en que se puede tener conciencia del mismo, incluido en la propia historia, cuando puede mover a la risa, o, en términos benjamineanos, producir una "experiencia" (BENJAMIN, 1991, pp. 111-134). La iteración del "mecanismo" en el poema se corresponde con instancias de introspección propias de cada edad: el recuerdo de la muerte del padre al cerrar el libro, el momento de comprensión de la propia mortalidad al dispararse el arma, el despertar sexual, nuevamente el recuerdo de la propia mortalidad al ser casi golpeado por el rebote del disparo, la conciencia del mundo y su complejidad al escuchar el temporizador de los semáforos al regresar solo y de noche, la madurez alcanzada con el exilio evitando la leva para ir a Vietnam, y la revisión entera de la propia vida desde la distancia temporal y geográfica. Estos recuerdos, asimilados en los instantes en los que se toma conciencia del mecanismo, se corresponden a la descripción de fragmentos de vida, casi instantáneas que repiten la écfrasis de las fotos, que marcan cortes en la propia historia, asimilando los momentos centrales para la experiencia personal a la división física a lo que ocurre dentro del mecanismo, al tomar una fotografía: "Siempre / Dividiendo esto de aquello" (vv. 102-103). Los momentos están asociados vivamente a los olores que se desprenden por el accionar del mecanismo. Se trata del sentido más difícilmente aprehensible por medios técnicos y sin embargo el más fuertemente asociado a la "memoria involuntaria" descrita por Proust (y que es fundamental para el concepto benjamineano de "experiencia"):

El olor es el refugio de lo inaccesible de la memoria involuntaria. Difícilmente se asocia con representaciones visuales; entre las representaciones sensoriales sólo se emparejará con el mismo olor. Si el reconocimiento de un aroma tiene, antes que cualquier otro recuerdo, el privilegio de consolar, tal vez sea así porque adormece la conciencia del paso del tiempo. Un aroma deja que se hundan los años en el aroma que recuerda. (BENJAMIN, 1998, p.158) 
Esto es visible en el caso del olor de la brea de la sierra eléctrica que come "hacia adentro de las décadas" (v. 33), donde se pone en tensión la temporalidad orgánica y la del mecanismo que libera el olor, pero supone también una violencia creadora. O, nuevamente, el olor del aserrín en el aserradero familiar. Y luego el "extraño aroma brillante de savia" que "revive" (v. 139) con el balazo que perfora la baranda de la escalera. $Y$ aquí cabe retomar los sonidos incidentales del poema en su forma digital: las únicas dos irrupciones sonoras remiten a disparos: del obturador primero y del arma después.

El "disparo" detiene la vida, produciendo una imagen o la muerte. Se establece entonces la relación, recurrente, entre la imagen fotográfica y la muerte, subrayada también por el título que describe a un álbum de fotos como el libro de los muertos ${ }^{11}$. Dos conceptos benjamineanos son fundamentales para nuestra interpretación. El de "experiencia", que incluye a la muerte como la instancia última de transmisión de la misma, y que se complementa con la idea de "memoria involuntaria", vinculada a aquellos recuerdos que no podemos controlar. A la memoria técnica, controlable, discreta como la de las fotografías o los periódicos, se contrapone esta forma de memoria imprevisible que irrumpe en el orden del pensamiento racional y que, en el poema, revela el paso del tiempo y la acción de la técnica sobre la naturaleza a través del olor de la madera, cautivo en las formas de la carpintería y que la propia técnica libera en un disparo accidental. Benjamin indica un quiebre entre la "rememoración" de la "memoria involuntaria" y los registros técnicos:

Si llamamos aura a las representaciones que, asentadas en la
memoria involuntaria pugnan por agruparse en torno a un objeto
sensible, ese aura corresponderá a la experiencia que como
ejercicio se deposita en un objeto utilitario. Los procedimientos
fundados en la cámara fotográfica y en otros aparatos similares
posteriores amplían el radio de la memoria involuntaria; hacen
posible fijar por medio del aparato y siempre que se quiera un
suceso en su imagen y en su sonido. Se convierten así en
asecuciones de una sociedad en la que el ejercicio se atrofia.
(BENJAMIN, 1998, p. 161)

${ }^{11}$ El título también presta lecturas diversas ya que por la indistinción entre singular y plural, podría estar aludiendo a "El libro del muerto", es decir, el padre. Optamos por la traducción más inclusiva en plural (el padre, pero también el resto de su familia).

Texto Digital, Florianópolis, v. 8, n. 2, p. 19-52, jul./dez. 2012. ISSNe: 1807-9288 
La lectura benjamineana coincide con la división eterna de "esto y aquello" ( $\mathrm{v}$. 103). En el poema, el uso no intencional del objeto técnico provoca lo inesperado, disparando un acontecimiento que escapa del orden de lo previsible y cotidiano. Esto genera una experiencia que está a la permite la toma de conciencia del mecanismo, al que se relaciona con la memoria de infancia. La relación se da en aquellos momentos significativos, que marcan grandes cambios en la vida y que en el poema son la percepción de la propia mortalidad, de la mortalidad de los padres, el descubrimiento del deseo sexual, el descubrimiento de la vocación y el exilio. La memoria técnica, por otra parte, se auratiza. Perdidos los negativos, el viejo álbum deviene objeto único, un libro de los muertos que pone en funcionamiento a la memoria involuntaria y que permite con ello hacer experiencia al insertar la propia vida en un contexto histórico particular, donde tradición y modernización colisionan. Aquí consideramos necesario recuperar el otro rasgo del concepto benjamineano de "aura".

Como indicamos antes, Benjamin afirmaba que los retratos, las fotografías donde todavía hay rostros humanos, son el último reducto cultural de un medio progresivamente tecnificado, arrancado de la práctica artesanal e inserto en la lógica de producción capitalista. Las fotos del libro de los muertos no son postales ni documentos, son fotos de familia, imágenes cuya referencialidad es intransferible ya que cobran sentido pleno al introducirse en una historia familiar y personal. Y desencadenan rememoraciones propias de la "memoria involuntaria", signadas por olores, antes que la "disposición constante del recuerdo voluntario, discursivo, favorecida por la técnica" (BENJAMIN 1998, pp.161-162). Se trata de un caso en el que la separación entre hombre y técnica aún es salvable, precisamente porque en el descubrimiento adolescente, como en la época de transición en la que el abuelo maneja la sierra eléctrica, el "ejercicio" no está atrofiado como en la etapa industrial (y adulta) posterior. No es por ello caprichoso que los muertos, que permiten al yo poético comprender su propia historia, estén en el tránsito de lo rural a lo urbano, de lo particular a lo global, de lo artesanal a lo industrial. La instancia de tensión y transición puede verse en el 
modo en el que el yo poético inserta los hechos en una tradición local cuando menciona que las veredas de ladrillo de Wheeling, "conocieron las herraduras de los caballos yanquis" (v. 175) para remitir a la Guerra Civil norteamericana, frente al año de la muerte del padre que aparece contextualizado en una tradición industrial: antes de morir llegó a conocer la caja de transmisión Torqueflite. Así hay una nueva contraposición: entre la herradura, propia de un modo artesanal de producción, y la caja de transmisión, plenamente industrial, ambas asociadas a los modos de transporte de la época y las huellas que dejan en el tiempo.

En función de esta diferencia de tradiciones, vale la pena destacar la disonancia rítmica que introducen dos pasajes casi en prosa versos 160-175 y 178-181, respecto de la versificación libre del poema. El primero describe la casa familiar en Wheeling e introduce un breve momento narrativo en la sucesión de imágenes (fotográficas o recordadas), el segundo es la publicidad de un automóvil que está guardada junto al álbum o quizá envolviéndolo. Aquí se produce una representación textual de la escritura de avisos clasificados, con abreviaturas y yuxtaposición de sustantivos sin verbo, limitándose a enumerar las características del producto, en este caso, del auto, y su precio. El cambio abrupto de registro intercalado en las écfrasis resulta disruptivo por tres motivos. En primer lugar, por alterar la versificación previa y en segundo por introducir un objeto técnico fechado para remitir elípticamente a la propia historia familiar del yo poético, al afirmar en los versos que siguen "Él llegó hasta la época de la radio, la caja de transmisión Torqueflite / pero no mucho más allá, y nunca en ese pueblo" (vv. 182-183). Un dato autobiográfico ofrece una pista para elucidar estos versos: El padre de Gibson murió en un viaje de negocios cuando él, que había nacido en 1948, tenía ocho años (ADAMS, 2007).

Así, la muerte del padre está fechada a partir de la aparición de una caja de cambios automática que comenzó a ser utilizada por Chrysler en $1956^{12}$. Este detalle, aparentemente fútil, en realidad apunta a la profunda imbricación entre la propia vida y la inscripción histórica de los objetos técnicos. Y, por último, la idea

12 Una historia de las cajas Torqueflite puede encontrarse en:
$<$ http://www.allpar.com/mopar/torqueflite.html>.


de una publicidad entre los versos del poema, se corresponde con las sobreimpresiones de publicidades de productos tecnológicos novedosos de la primera mitad del siglo XX sobre las representaciones del ADN en los grabados de Ashbaugh en Agrippa, estableciendo una nueva imbricación entre vida y técnica, entre tecnologías de registro (las representadas en las sobreimpresiones) y representaciones de representaciones tecnológicamente mediadas del código de la vida (la electroforesis en gel), pero también entre los distintos elementos que componen la obra.

\section{Lecturas críticas de Agrippa: Apocalípticos y Elegíacos}

Como señala Henthorne (2011, p.19), el poema "Agrippa" es considerado un hecho seminal de la literatura digital y a pesar de ello su texto ha sido objeto de menos comentarios críticos que las particularidades técnicas del proyecto Agrippa. Existen dos textos académicos que se ocupan del poema en sí: "Agrippa, or the Apocalyptic Book" ["Agrippa, o el libro apocalíptico"] (SCHWENGER, 1994) y "Destructive Creativity: The Arts in the Information Age." ["Creatividad destructiva: Las artes en la era de la información"] (LIU, 2004). Si bien tienen una pretensión totalizadora, oscilan entre una definición temática y de tono, y una discusión sobre el concepto del proyecto y el poema en sí, así como su particular representación digital, sin distinciones claras de lo que en este trabajo definimos como a) Agrippa, b) "Agrippa" y c) el código que se autoencripta.

La lectura de Schwenger señala la influencia de Blanchot en la idea de libro que se autoconsume y discute la iteración de la imagen poética del mecanismo que articula el poema. Si bien su lectura aporta una buena contextualización general para una primera aproximación al texto, adolece de muchas imprecisiones en lo relativo a los aspectos técnicos y a lo que efectivamente pudo concretarse en el objeto Agrippa. Schwenger se aboca a rastrear las influencias del postestucturalismo en la obra, sin integrar su análisis con una discusión específica sobre la imbricación entre los aspectos técnicos del proyecto Agrippa (la materialidad de la obra, los aspectos relativos al software de autencriptado), su 
relación con los aguafuertes de Ashbaugh, los temas y los recursos formales y expresivos del poema. La idea de apocalipsis organiza el artículo, remitiendo más a discusiones sobre los distintos "fines de", del libro, de la historia, de la memoria, y desconociendo la tensión entre el encriptado y la libre accesibilidad puesta en juego desde el texto y desde el proyecto por su desafío implícito al submundo hacker.

El poema autoencriptable condensa la experiencia perceptiva y la imbrica con su tema (la relación entre memoria y dispositivos de registro). Pero la posibilidad su crackeo no clausura la obra ante una teleología de la técnica, sino que invita a subvertirla. A pesar de la reauratización que provoca saber de antemano la existencia del autoencriptado, el texto digital entraña, en tanto código, una reproductibilidad técnica que demolería su aura. Por ello, si la imposición de un autencriptado en algunos pudo generar esa atención sostenida, en otros generó el desafío y la expectativa de desmontar tal unicidad mediante el crackeo del código $^{13}$. La sola posibilidad de que esto ocurriera, y que de hecho se concretó al día siguiente su presentación pública, hace que el aura de Agrippa sea un aura parcial y provisoria. Parcial porque sólo el objeto-libro la mantiene, y provisoria porque el autoencriptado funciona en tanto no accedamos a la versión reproducida on-line y nos sometamos a las reglas impuestas por el proyecto Agrippa $^{14}$.

Entendemos que aunque correcta, la lectura de Schwenger es propia de los estudios literarios tradicionales que no se ocupan de relevar las dimensiones fundamentales de la interrelación entre de los múltiples niveles de Agrippa y la necesidad de contemplar las poéticas tecnológicas que animan el proyecto. Por ejemplo, la referencia temática a la ausencia de los familiares ya muertos y su

\footnotetext{
13 "Templar", uno del los responsable del crackeo lo presentó en el BBS MindVox diciendo que se trataba del "último vellocino dorado" de la comunidad hacker (Templar 2005).

${ }_{14}$ Striphas (2009) señala a Agrippa como precursor de los límites a la copia, impresión y circulación de archivos de que impone el software de DRM [Administración digital de derechos], pero otros sostienen que la obra también fue un ejemplo pionero de la práctica cada vez más común del crackeo de libros con DRM para liberar su circulación digital (Lankinen 2012)
}

Texto Digital, Florianópolis, v. 8, n. 2, p. 19-52, jul./dez. 2012. ISSNe: 1807-9288 
recobrada presencia gracias a las tecnologías de registro -indudablemente uno de los rasgos principales del poema- recibe apenas un comentario marginal.

La lectura de Liu propone una comparación entre el poema de Gibson y "Lines Written a Few Miles above Tintern Abbey" ["Versos escritos pocas millas más allá de la Abadía de Tintern"] de William Wordsworth partiendo de la premisa de que en ambos poemas se tematiza el momento de la pregunta por la identidad y por la vocación de escritor del yo poético. Liu sugiere que en Gibson hay un tono que atraviesa tanto el poema como su narrativa cyberpunk, al que considera "elegíaco". Para el crítico, el eje que articula ambos poemas, el de Gibson y el de Wordsworth, es la tensión destrucción-creación (y al hacer esto efectivamente vincula el tema con el soporte material y con el procedimiento de la autodestrucción que puede ser crackeada y luego, en el ciberespacio, difundirse y mutar). Sin embargo, lo sorprendente es la atribución a Gibson de una herencia romántica: 'Like Wordsworth's poetry, then, 'Agrippa' is a testament to loss that in the end becomes a new testament of recuperation. Gibson's neuromanticism is indeed a disciple of Romanticism"15 (LIU, 2004, p.345).

En el caso de Gibson, para Liu, la idea de "la naturaleza" como fuente de inspiración de Wordsworth encontraría su equivalente en "el mecanismo": "What is authorial inspiration? Fundamentally, Wordsworth and Gibson answer, it is obeisance to a terrifying, autonomous agency without that is somehow also a poetic agency within"16 (LIU, 2004, p.346). Más allá de las equivalencias algo caprichosas entre las biografías de los autores (muerte del padre, recuerdos del primer hogar, partida), la idea de una "agencia autónoma" no se corresponde, como ya hemos discutido, con las tensiones inherentes al "mecanismo", y en ello estriba una diferencia fundamental que vuelve forzada la tesis de Liu. La toma de

\footnotetext{
15 "Como la poesía de Wordsworth, entonces, 'Agrippa' es un testamento de la pérdida que al final se vuelve un nuevo testamento de recuperación. El neuromanticismo de Gibson es de hecho un discípulo del romanticismo"

${ }_{16}$ "¿Qué es la inspiración autorial? Es, responden Wordsworth y Gibson, fundamentalmente la obediencia a una agencia terrorífica y autónoma externa que es, de algún modo, también la agencia poética dentro"
}

Texto Digital, Florianópolis, v. 8, n. 2, p. 19-52, jul./dez. 2012. ISSNe: 1807-9288 
conciencia respecto del mecanismo supone una capacidad de acción que la certeza de la vocación artística del yo poético de Wordsworth no contempla.

El mecanismo es de fabricación humana y, aunque moldee la vida de los hombres, también puede ser moldeado, siempre que seamos concientes de su existencia junto a la nuestra. Por ello el programa flusseriano de intervención sobre el dispositivo en aras de recuperar la libertad parece más pertinente que la aceptación gozosa de una fuerza superior liberadora o aterradora. La invitación al crackeo del código, que estuvo presente desde los inicios del proyecto, propicia tal búsqueda de libertad: recuperar la memoria, arrancándosela a la máquina, y no a recibirla como una gracia otorgada. El tono elegíaco, el canto a algo que se pierde, no se puede parangonar con la comprensión ganada con la toma de conciencia del "mecanismo". La posibilidad de "hacer experiencia" en el contexto de transición del mundo tradicional al mundo industrial implica una posibilidad de acción política y no la maduración de una comprensión serena. La posición política es un elemento central en el rupturismo de la narrativa de Gibson respecto de la ciencia-ficción de los ' 80 , que él consideraba se había vuelto conservadora y despojada de todo su potencial contracultural (ADAMS, 2007).

En este sentido sus influencias beatnik ofrecen una mejor clave que el romanticismo para entender la estética implícita en el título de su primera novela, Neuromancer. Más que un nuevo romántico, como sugiere Liu, se trata de un nuevo novelista, y más que novelas de formación, las suyas resultan novelas de la deformación. Alguien que altera las reglas de un género que había devenido un lugar de pérdida de la narración, como las novelas decimonónicas que Benjamin critica, para recuperar su potencial de transmisión de experiencia. Los personajes de Leskov remiten a un mundo rural en vías de desaparición (y casi idealizado) cuando Benjamin escribió su ensayo, radicalmente opuesto a una alegoría del presente en un futuro distópico, ultratecnificado e hipercapitalista.

En cambio, entendemos que la posibilidad de narración, de transmisión de experiencia que reaparece en los personajes de Gibson reside en la búsqueda de 
sentido en las fisuras de la cultura industrial y en los diversos pasados ligados a tradiciones técnicas que mantienen una impronta artesanal y que perviven en sus márgenes. Los personajes gibsonianos no se corresponden con un recogimiento metafísico sino más bien con una muy terrena relación autodidacta con la tecnología para sobrevivir, un ejercicio no "atrofiado" de los dispositivos, recuperando la referencia benjamineana.

Al relacionar el objeto libro y el poema, la lectura de Liu retoma la figura del apocalipsis de Schwenger: "Agrippa, to start with, is a book whose physically distressed form enacts Gibson's distinctive patina of destructivity. As described by Peter Schwenger in a perceptive article, Agrippa is an artifact of catastrophe"17 (LIU 2004, p.339). En cierto modo, ambos autores proponen encuadrar el poema de Gibson en el contexto de los futuros sórdidos de las primeras ficciones de Gibson. Como hemos señalado, esto supone reducir las distintas temporalidades que construye en su obra (futuro cercano, futuro inminente, pasado alterno, pasado extremadamente reciente) para referirse a las persistentes tensiones del presente:

We first notice it when Ashbaugh's images (at least as the book was originally conceived) alter in appearance like some picture of Dorian Gray updated to the processes of pixel-rot, gene-splicing, or molecule-creep that are the usual symptoms of cyberpunk's fetishization of digital, biotech, and nanotech fungibility ${ }^{18}$. (LIU, 2004, p. 440)

La referencia recurrente a un apocalipsis técnico, enmarca forzosamente el texto en el cyberpunk en lugar de contemplarlo en relación a toda la obra de Gibson (y al momento cultural en el que estaban haciendo su irrupción efectiva las tecnologías digitales). Al mencionar las ambiciones del proyecto original sin considerar las elecciones materiales efectivamente realizadas para llevar a cabo

\footnotetext{
17 "Agrippa, para comenzar, es un libro cuya forma físicamente envejecida representa la pátina distintiva de la destructividad de Gibson. Como fue descripto en un perspicaz artículo por Peter Schwenger, Agrippa es un artefacto de catástrofe."

18 "Lo detectamos primero cuando las imágenes de Ashbaugh (al menos de acuerdo a como el libro originalmente fue concebido) se alteran, aparentemente como un cuadro de Dorian Gray actualizado al proceso de putrefacción de los píxeles, costura de genes, o malestar molecular que son los síntomas usuales de la fetichización cyberpunk de la fungibilidad digital, biotecnológica y nanotecnológica."
} 
la idea original (como usar tóner sin curar), se mantiene un idealismo que ignora lo que esa decisión ilumina: las constantes negociaciones entre idea y materia en un contexto tecnológico históricamente determinado. El romanticismo que Liu ve en Gibson es en realidad el del propio Liu, que sigue pensando en la idea de genio creador de la obra como su rasgo esencial en lugar del proceso efectivo de su concreción:

In one regard, Gibson's "Agrippa" is fully Romantic because like "Tintern Abbey" it also answers the tandem questions "who am I?" and "who am I as a writer?" by equating artistic identity with a fundamentalism of personal memory. Indeed, Gibson's poem is so much a work of memory that it might be called memory to the second power: it takes as its framing device an antecedent memory-book-a photo album - whose combined appearance of decay and clarity sets the scene for the poem's meditation on destructivity and recuperation ${ }^{19}$. (LIU, 2004, p. 341)

El análisis de Schwenger y, en menor medida, el de Liu, retoman tópicos recurrentes de las lecturas apocalípticas, ahora en el sentido de la clásica división de la relación ante la industria cultural propuesta por Umberto Eco. Entendemos que la elegía o el apocalipsis son lecturas de época (muy a tono con la idea de "fin del libro") mientras que, por el contrario, en Gibson, el futuro y el pasado son alegorías del presente. Desde nuestra perspectiva la poética de Gibson consiste en la figuración de un presente hecho de tensiones y conflictos éticos, políticos y sociales, pero también estéticos, antes que un canto de réquiem por una cultura humanista en retirada ante el avance técnico.

Este énfasis en el apocalipsis como un símbolo de lo inefable eclipsa la importancia de la gradualidad temporal, de la relación entre olvido y obsolescencia, contracaras de la relación entre memoria y técnica. La idea de reliquia post-apocalíptica es una imagen absoluta que no se corresponde con la

\footnotetext{
19 'En un sentido, el 'Agrippa' de Gibson es totalmente romántico porque como 'Tintern Abbey' también responde a las dos preguntas '¿quién soy yo?' y '¿quién soy yo como escritor?' equiparando la identidad artística con un fundamentalismo de la memoria personal. De hecho, el poema de Gibson es una obra de la memoria de modo tal que podría denominarse memoria a la segunda potencia: toma como su dispositivo de contextualización un libro de memoria precedente -un álbum de fotos- cuya apariencia combinada de deterioro y claridad prepara la escena para la meditación del poema sobre la destructividad y la recuperación."
} 
gradualidad lenta del progreso que atraviesa toda la obra de Gibson. La superposición de temporalidades pervive y disputa con la teleología del progreso, en la cual el fin de los tiempos nunca sucede. Por el contrario, se repite la idea de la técnica como generador, no siempre planificado, de pasados que se sobreimprimen al presente o sobreviven en sus márgenes. Se trata de una lectura no teleológica del progreso técnico, donde la historia nunca llega a su fin sino que resurge en los márgenes de la sociedad. Por ello, entendemos que la representación conflictiva de la memoria que se construye, tanto en la obra en general como en el poema en particular, es más aprehensible bajo figuras graduales como la acumulación de múltiples pasados en el presente. Benjamin lo describió certeramente con la imagen de tormenta que arrastra las alas del ángel de la historia forzándolo a mirar hacia atrás y contemplar la acumulación de ruina sobre ruina, documentos de barbarie que revelan la historia oculta de los vencidos. O en la imagen irónica y pedestre de "putrefacción de los bits" que elige Gibson para dar cuenta del peculiar devenir de "Agrippa": "Meanwhile, though, the text escaped to cyberspace and a life of its own, which I found a pleasant enough outcome. But the free-range cyberspace versions are subject to bit-rot"20 (GIBSON, 2002).

No obstante, los análisis antes citados iluminan algunos aspectos muy relevantes del libro, que deben ser considerados relativizando la importancia otorgada al leitmotiv apocalíptico, más presente en las críticas que en el poema. El aporte más importante de Liu a una aproximación crítica a "Agrippa" está en su discusión sobre la relación entre la división de la vida por la técnica (como en la fotografía, pero también en los campos de concentración, en la guerra de trincheras, en los controles migratorios), y los procedimientos artísticos vanguardistas del siglo XX. Los mecanismos de la época industrial, basados en el estándar, funcionan en base a unidades discretas y no de continuos, del mismo modo que opera la racionalidad estatal y la económica. Y del mismo modo procede el arte vanguardista, sugiere Liu. Sólo que al hacerlo se dirige en un sentido opuesto.

\footnotetext{
20 "Mientras tanto, sin embargo, el texto escapó al ciberespacio y a una vida propia, lo cual considero una solución bastante agradable. Pero las versiones al aire libre de ciberespacio están sujetas a la putrefacción de los bits."
}

Texto Digital, Florianópolis, v. 8, n. 2, p. 19-52, jul./dez. 2012. ISSNe: 1807-9288 
Benjamin señalaba que si bien en la técnica reside el riesgo de una "estetización de la vida" utilizable por el fascismo (pero también por el capitalismo, como sugiere al hablar de los estudios de cine norteamericanos), también puede "politizar al arte" (BENJAMIN, 1989, p.57). Sin discontinuidades no hay escritura, ni fotografía, ni mucho menos representación digital, pero sin esas discontinuidades tampoco puede hacerse estallar las tradiciones literarias y artísticas como lo hace Agrippa.

Más que a un apego al cyberpunk, a una recurrencia de la sordidez tecnológica, entendemos que la remisión a una écfrasis de fotografías de la década de 1920 es indicativa del rasgo distintivo de toda la obra de Gibson, el "nominalismo posmoderno" señalado por Jameson. El procedimiento aborda la temporalidad de la técnica (y lo que su obsolescencia ilumina) y es inherente al proceso de descripción de lo técnico mediante la referencia a la marca. Este procedimiento constituye la base de la escala de invariantes para el poema y requiere especial atención en nuestra traducción. Hemos optado por mantener la referencialidad de las marcas y objetos mediante el uso de notas a pie. De este modo, el poema Gibson inscribe a los objetos en la historia (tanto la personal como la mundial) y el procedimiento de inscripción lo constituye como exponente de una nueva estética literaria:

But it is by way of its style that we can best measure the new literature on some kind of time-continuum; and here we may finally return to the distinctiveness of Pattern Recognition, where this style has reached a kind of classical perfection. I will define it as a kind of hyped-up name-dropping [...] I have no idea whether all these items actually exist but eBay is certainly the right word for our current collective unconscious, and it is clear that the references "work", whether or not you know that the product is real or has been made up by Gibson. What is also clear is that the names being dropped are brand names, whose very dynamic conveys both instant obsolescence and the global provenance and neo-exoticism of the world market today in time and space.

A further point is that, little by little, in the current universe, everything is slowly being named; nor does this have anything to do with the older Aristotelian universals in which the idea of a chair subsumes all its individual manifestations. [...] Each of these items is on its way to the ultimate destination of a name of its own, but not the kind we are familiar with when we speak of a "Mies chair" 
or a "Barcelona chair". Not the origin, but rather the named image is at stake, so that an "Andy Warhol electric chair" might be a better reference. ${ }^{21}$ (JAMESON, 2003, pp.108-109)

Lo que es novedoso de Agrippa tanto respecto de toda la obra de Gibson, como de la literatura digital en general, es la articulación de su materialismo y su modo de representar un Zeitgeist con una existencia material aurática que contiene en sí las bases de su reproductibilidad técnica a la vez que atenta contra las mismas en el objeto libro y el diskette.

En el espacio crítico latinoamericano hay dos referencias a la obra. Un ejemplo de cómo el impacto cultural de Agrippa ha sido muchas veces sobredimensionado o no muy comprendido es el del crítico brasileño Arlindo Machado, una autoridad en el campo de las artes mediales. Machado inscribe a Agrippa en una genealogía de intervenciones sobre los dispositivos, o "máquinas semióticas" junto con las obras del videasta Nume June Paik y los fotógrafos Frederic Fontenoy y Andrew Davidhazy. Luego, la define como una "novela digital" que

coloca en la pantalla un texto que se confunde y se destruye gracias a una especie de virus de computadora capaz de detonar los conflictos de memoria del aparato -entonces no se puede más decir que los artistas están operando dentro de las posibilidades programadas y previsibles de los medios indicados. Ellos están, en verdad, sobrepasando los límites de las máquinas semióticas y reinventando radicalmente sus programas y sus finalidades. (MACHADO, 2007, p. 14)

\footnotetext{
21 "Pero es a través de su estilo que podemos estimar mejor a la nueva literatura en algún tipo de continuo temporal; y aquí podemos volver a los rasgos distintivos de Pattern Recognition, donde este estilo ha alcanzado una especie de perfección clásica. Definiré a la misma como una forma exagerada de mención de nombres al pasar [...] No tengo idea de si todos estos ítems existen pero eBay es ciertamente la palabra correcta para nuestro estado actual de inconsciente colectivo, y está claro que las referencias 'funcionan', más allá de que uno sepa o no que el producto es real o ha sido inventado por Gibson. Lo que también está claro es que los nombres mencionados al pasar son nombres de marcas, cuya propia dinámica expresa tanto la obsolescencia instantánea como el origen global y el neo-exotismo del mercado mundial de hoy en el tiempo y el espacio.

Un punto adicional es que, de a poco, en el universo actual, todo está siendo lentamente nombrado; no tiene esto nada que ver con los viejos universales aristotélicos en los cuales la idea de una silla subsume a todas sus manifestaciones individuales. [...] Cada uno de estos ítems es en su camino a su destino final, un nombre propio, pero no del modo con el que estamos familiarizados cuando hablamos de una 'silla Mies' o una 'silla Barcelona'. No es el origen sino más bien la imagen nombrada lo que está en juego, de tal modo que una 'silla eléctrica Andy Warhol' podría ser una referencia más adecuada."
} 
Más allá de los errores en lo relativo al "virus" y a la intervención sobre el hardware ("la memoria del aparato"), aquí resulta patente una lectura forzada de la obra tendiente a avalar una poética flusseriana de intervención sobre el dispositivo a la que Machado se adscribe. No obstante, en el caso de Agrippa la tecnología utilizada para autoencriptar el archivo no fue un virus sino un algoritmo conocido como RSA, desarrollado por el Massachusetts Institute of Technology. Aunque Machado parece tomar en cuenta la importancia de la obra en el campo, su único conocimiento de la misma parece provenir de la lectura de notas periodísticas y no de la obra en sí.

El segundo aporte es de Christian Ferrer, que le dedica tres páginas en su extenso ensayo Mal de ojo. Su texto ilumina aspectos temáticos dejados de lado por la crítica norteamericana sobre Agrippa, a pesar de algunas imprecisiones que acaso se deban a la extrema dificultad de acceso a la obra en su soporte material. $^{22}$ En lugar de tópicos tecnofílicos o tecnofóbicos, Ferrer resalta cómo Agrippa interpela al lector en torno al problema de la "obsolescencia":

Pero hay aún otra significativa muesca en el extraño libro de Gibson: el recurso a las publicidades antiguas de tecnologías ya anacrónicas. ¿Cree Gibson que nuestros vínculos con las máquinas se evidencian mejor cuando son dejadas de lado por la moda o cuando sufren el anatema rotativo: la bula de la obsolescencia? Cuando prestamos atención a las viejas máquinas [...] y las contemplamos herrumbradas, silenciosas y abandonadas, aguardando en hangares y depósitos su oxidación final, nos damos cuenta que ellas también nos ayudan a entender nuestra propia fragilidad. Condenadas al desguace o a la tienda de anticuario [...] comprendemos que ni ellas nos sirvieron ni nosotros supimos incluirlas en un dominio espiritual que las

\footnotetext{
${ }^{22}$ Entre las imprecisiones se describe al texto como poema en prosa cuando está en verso libre, el proceso de representación en scroll down y posterior encriptado como virus no es correcto, señala que el $A D N$ que repiten las páginas impresa es humano cuando en realidad se trata del ADN de la mosca Drosophila, y, por último, se refiere en repetidas oportunidades al "libro de Gibson" sin menciones a Ashbaugh y Begos. Cabe señalar que este detalle da cuenta de un matriz idealista, hace del texto un rasgo esencial de la obra, sin mención alguna a Ashbaugh, Begos o los ingenieros que escribieron el código que encripta el poema. Sólo "Agrippa", el texto del poema, que es justamente lo que se filtró a internet y es de acceso público, parece ser relevante para hablar de Agrippa. El concepto de autor tiene una relevancia muchas veces dejada de lado en el momento de aproximarse a este tipo de obras desde categorías previas.
} 
redimiera. El óxido no es solamente el virus de las máquinas, también es la pátina melancólica de la historia. (2005, p. 135)

Ferrer explicita algunos de los tópicos centrales del poema: la relación entre la experiencia cotidiana de la tecnología y la memoria, articulada a partir de la écfrasis de las fotografías familiares. El texto de Ferrer también apunta a un efecto estético de orden formal: "El virus en el libro de Gibson oficia a modo de augur: nos purga del exceso de información y de palabras huecas y nos devuelve a la elocuencia del soplo harapiento" (2005, p.135). Aunque el proceso de autencriptado no sea un virus, sí logra el efecto de condensación de la atención que señala Ferrer. Otro aspecto distintivo de su lectura, acaso por su pensamiento situado en la modernidad periférica propia de América latina sea reparar en el rol de la obsolescencia para aproximarse poéticamente a la relación entre técnica y experiencia.

\title{
Traducción crítica de "Agrippa"
}

A continuación ofrecemos la segunda parte del poema original extraída del texto que estaba en el archivo encriptable original (WIEDIJK, 2011) y la segunda parte de nuestra traducción. Como señalamos antes, una traducción "completa" supondría reemplazar el texto del archivo autoencriptable original, luego compilarlo para obtener un archivo ejecutable que funcione en un emulador del sistema operativo para el que fue previsto, el de la Apple II:

\author{
"Agrippa (A Book of the Dead)" \\ II. \\ El mecanismo: metal negro estampado \\ Cuerina sobre cartón, pedazos de boj, \\ Un lente \\ El obturador $\mathrm{cae}^{23}$ \\ Siempre
}

\footnotetext{
${ }^{23}$ Al aparecer esta línea en la pantalla se oía un sonido que remitía al obturador de una cámara fotográfica. En la emulación realizada por The Agrippa Files el sonido es apenas un ruido. Puede deberse a las limitaciones técnicas del sampleo del sonido original (si es que fue sampleado) o a incompatibilidades propias de la emulación.
} 
Dividiendo esto de aquello.

Ahora en dormitorios de techos altos

desocupados y sin visitas

en los últimos cajones de escritorios enchapados

en la fría oscuridad química se enrollan montajes

conmemorativos de los muertos del país en las Guerras

Mundiales,

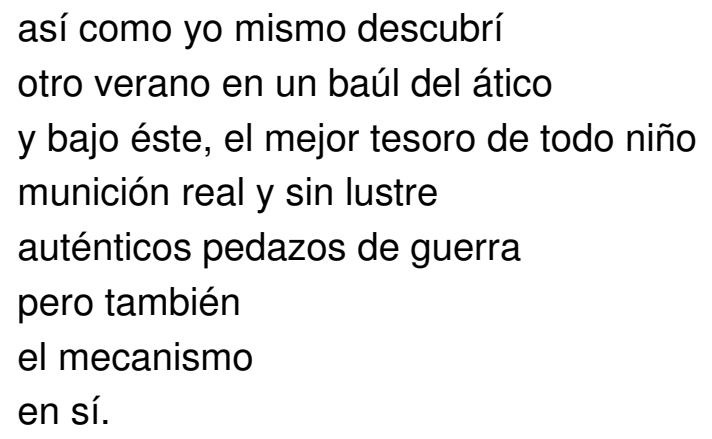

La terminación pavonada de las armas de fuego es un proceso, controlado, derivado del óxido común, pero ahí

bajo una pátina tan poco común e infrecuente todos esos años sin ser tocada hasta que yo la tomé y volviéndome, extasiado, bajo la despintada escalera, hacia el vestíbulo donde, juro, nunca oí el primer disparo. ${ }^{24}$

La bala cubierta de cobre recuperada del baño del cilindro de cartón de la sal Morton ${ }^{25}$ no estaba deformada salvo por las débiles marcas brillantes del impacto y surcos

\footnotetext{
${ }^{24} \mathrm{Al}$ aparecer esta línea en la pantalla se oía un sonido que remitía a un disparo. En la emulación realizada por The Agrippa Files el sonido se asemeja más al modelo, que en el caso anterior del obturador, sin embargo su calidad técnica, para los estándares actuales (y para los de la época, en formato $C D$ o casete o disco) es muy pobre. Como en el caso del sonido del obturador, también puede deberse a las limitaciones técnicas del sampleo del sonido original (si es que fue sampleado) o a incompatibilidades propias de la emulación.

${ }^{25} \mathrm{La}$ sal Morton a la que se refiere puede ser la que se utilizaba en las recargas de los suavizantes de agua o descalcificadores en la época de las cañerías de bronce para evitar que se taparan por los minerales que se acumulaban.
} 
tan calientes, energía detenida, y ampolló mi mano.

El revólver yacía en la alfombra polvorienta.

Volviendo con un total sobrecogimiento lo tomé tan cuidadosamente

que el segundo disparo, tampoco intencionado, perforó la baranda de madera dura y revivió un extraño aroma brillante de savia en un rayo polvoriento de luz del sol.

Absolutamente solo con conciencia del mecanismo.

Como la primera vez que ponés tu boca sobre una mujer.

\section{Conclusiones: La vida de los textos y la resurrección de los archivos digitales}

En los veinte años que han transcurrido desde la aparición del peculiar libro que desaparecía propuesto por Begos, Gibson y Ashbaugh, ha ocurrido un desplazamiento del pronóstico del "fin del libro" hacia el temor por lo efímero de la información digital y su obsolescencia técnica. El problema de las aproximaciones a la producción digital desde las humanidades hoy planteado ya no es tanto la definición del objeto como su preservación (LIU et al., 2005; KIRSCHENBAUM et al., 2010). Sin embargo, las aproximaciones críticas existentes no suelen abordar problemas relativos a las relaciones entre una estética de lo digital y su dimensión política, o cuando lo hacen es desde miradas apocalípticas o integradas que suponen una mirada conservadora o teleológica del objeto. Si bien el problema excede el marco del presente trabajo, una aproximación crítica a las obras de la literatura digital debe tener en su horizonte una lectura compleja del problema de la técnica. La metodología ha ido ganando especificidad pero no hay muchas vinculaciones entre las obras digitales y su inserción en la cultura contemporánea, manteniéndose una tendencia inmanentista incluso en aquellas lecturas que ponen el énfasis en la necesaria dimensión material de las obras o la necesidad de categorías específicas para analizar las mismas. En todas sus 
particularidades, Agrippa constituye un objeto privilegiado para poder discutir las diversas tendencias que introduce en la cultura el fenómeno técnico en general y la digitalización en particular. Esto hace necesaria la reconstrucción crítica de su contexto de emergencia, así como el modo en el que se insinúan en torno a la obra prácticas y formas ligadas con el devenir de la cultura actual en la época de su digitalización. Por ello, consideramos necesario enfatizar sobre la necesidad de abordar la "imbricación" como espacio crítico sobre el cual trabajar las obras para no dejar de lado su especificidad sin caer en un formalismo digital.

Otro aspecto propio de la digitalización es que al codificar una obra, ésta puede ser reproducida en y desde soportes diversos, aún a riesgo de generar un "anacronismo de los contenidos", es decir, la reproducción o representación de una obra en un dispositivo de reproducción o soporte distinto de aquel para el que fue originalmente previsto (con las modificaciones que esto pueda generar en la percepción de la obra $)^{26}$. Por proponer un ejemplo contemporáneo, sería el caso de la contemplación de una obra cinematográfica (pensada para ser proyectada sobre una gran pantalla en una sala oscura) en la diminuta pantalla de un teléfono celular que emite la luz en lugar de recibirla y compite contra la luminosidad del ambiente. La idea de "remediación" (BOLTER; GRUSIN, 1999) si bien es pertinente para describir el fenómeno, es demasiado general para dar cuenta de las tensiones que surgen por el modo en el que las obras circulan en el contexto digital. Asimismo, la remediación es un concepto descriptivo tendiente a los fenómenos socio técnicos relativos a la circulación de contenidos digitales y no implica el rigor epistemológico necesario para la traducción de literatura experimental en general y digital en particular. Considerar el rol del arte y la literatura como mercancía y los modelos de industria cultural e instituciones culturales en los que está inserto es, por ello, un aspecto fundamental para repensar las obras artísticas en el contexto de una separación acrítica de las

\footnotetext{
${ }^{26}$ Para una discusión in extensum sobre el problema del anacronismo de los contenidos véase Mâquina e imaginário: O desafío das poéticas tecnológicas de Machado (1993: 28-30) y el ya clásico estudio de Umberto Eco sobre la industria cultural, Apocalípticos e integrados, en particular el problema del desfasaje cuando se adaptan obras cinematográficas a la televisión (2004: 368).
} 
mismas de sus soportes y su percepción como puras abstracciones comunicables.

El cambio de soportes que siguió el texto del poema "Agrippa", sus combinaciones con otros recursos expresivos, como fueron la lectura y proyección del texto de "Agrippa" el 9 de diciembre, el crackeo y su difusión digital viral, hacen de "Agrippa" un hito fundamental para abordar problemas de estética en la época de la reproductibilidad digital. Asimismo, la historia de la circulación cultural de Agrippa entendido como un "dispositivo artístico", la tensión entre artesanado e industria implícita en los elementos que lo componen, las connotaciones culturales desplegadas y su imbricación con el código, conforman una obra en la que pueden rastrearse prácticas propias de las vanguardias artísticas así como de los rituales del que proviene el resto aurático de las obras únicas. Esta obra ofrece también un ejemplo rico para abordar la relación necesariamente imbricada entre tema, soporte, almacenamiento, recursos constructivos, recursos poéticos, dispositivos de registro y de reproducción. Al llamar la atención sobre la "auraticidad" de las obras pero también sobre los límites y posibilidades de la digitalización, Agrippa propone una "politización del arte" (y la literatura) ante la "digitalización estetizada" y "contenidista" de la industria cultura en la época de la reproductibilidad digital.

En su singular registro "irrepetible", Agrippa replantea los problemas de la "experiencia" y de la "memoria" contemporáneas, haciendo evidente la ilusión de una estabilidad ante la creciente posibilidad de que el registro de todas las cosas sea conservado, fuera del tiempo, en los soportes, a través del "mecanismo". Y al mismo tiempo, Agrippa anticipa la revolución cultural que introducen la codificación binaria, su posterior decodificación y las mutaciones, en diversos dispositivos reproductores digitales. Es por esto que en Agrippa podemos postular una inscripción de las "experiencias" en el marco de una "tradición cultural" pero también en el de una "genealogía técnica". 


\section{A RESSURREIÇÃO DIGITAL DOS MORTOS: TRADUÇÃO E CRÍTICA DE UM MARCO DA LITERATURA DIGITAL}

RESUMO: O artigo propõe uma leitura crítica e um modelo de tradução para obras experimentais no contexto da literatura digital. No primeiro lugar, apresentamos o poema auto-encriptável de 1992 "Agrippa (A Book of the Dead)" ["Agrippa (Um livro dos Mortos)"] de William Gibson, que fazia parte do objeto-livro Agrippa ( $A$ Book of the Dead), obra em colaboração do próprio Gibson, o editor Kevin Begos e o artista plástico Dennis Ashbaugh. No segundo lugar, contextualizamos o contexto de emergência da obra e seu impacto. Na terceira seção, apresentamos as traduções existentes do poema y oferecemos uma proposta metodológica para a tradução. En função de nossa proposta de tradução, se apresenta um panorama da critica sobre a obra e da importância da leitura crítica e um fragmento do original e de nossa versão. Finalmente discutimos a importância da obra no contexto da digitalização.

PALAVRAS-CHAVE: Agrippa. Tradução. Poesia experimental. Literatura digital. William Gibson.

\section{Referencias}

ADAMS, T. Space to think. 2007. Disponible en: $<$ http://www.guardian.co.uk/books/2007/aug/12/sciencefictionfantasyandhorror.fea tures>. Accedido mayo 26, 2012.

BENJAMIN, W. Discursos interrumpidos. In: Filosofía del arte y de la historia. vol. 1. Madrid: Taurus, 1989.

. lluminaciones IV. Para una crítica de la violencia y otros ensayos. Madrid: Taurus Humanidades, 1991.

. lluminaciones II: Poesía y capitalismo. Madrid: Taurus, 1998.

Sobre la fotografía. Valencia: Editorial Pre-Textos, 2004.

BERTI, A. Agrippa (Un libro de los muertos): El soporte y la representación de la memoria. In: Representaciones. vol. 4, n.2. 2010.

BOLTER, J.D; GRUSIN, R. Remediation. Understanding new media. Cambridge: Mass.: MIT Press, 1999.

FERRER, C. Mal de ojo: crítica de la violencia técnica. Buenos Aires: Colihue, 2005.

GIBSON, W. Source Code. In: Official Website. 2002. Disponible en: $<$ http://www.williamgibsonbooks.com/source/source.asp >. Accedido mayo 4, 2012.

Agrippa, Un libro de los muertos. In: La tumba del pardo. 2008a. Disponible en: <https://immorfo.wordpress.com/2008/04/22/agrippaun-libro-de-losmuertos/>. Accedido mayo 25, 2012. 
Agrippa (Un Libro de Los Muertos). 2008b. Disponible en: $<$ http://es.scribd.com/doc/6732324/GIBSON-William-Agrippa-Un-Libro-de-LosMuertos >. Accedido mayo 25, 2012.

Literaria.

Agrippa, un libro de los muertos. In: La idea fija. Revista Bastante en: $<$ http://www.laideafija.com.ar/especiales/gibson/GIBSON aggripa.html>. Accedido mayo 25, 2012.

GRIEU, F. Analysis of Agrippa Disk Image. In: The Agrippa Files. 2008. Disponible en: <http://agrippa.english.ucsb.edu/grieu-franois-grieu-analysis-ofagrippa-disk-image $>$. Accedido mayo 25, 2012.

HAYLES, N.K. Electronic Literature: What is it? In: The Electronic Literature Organization. 2007. Disponible en: <http://eliterature.org/pad/elp.html>. Accedido abril 3, 2012.

HENTHORNE, T. William Gibson: a literary companion. Jefferson: McFarland, 2011.

JAMESON, F. Fear and Loathing in Globalization. In: New Left Review. vol. 23, 2003, p. 105-114.

KIRSCHENBAUM, M. G. et al. Digital forensics and born-digital content in cultural heritage collections. Washington D.C.: Council on Library and Information Resources, 2010.

KIRSCHENBAUM, M.G. Mechanisms: new media and the forensic imagination. Cambridge: MIT Press, 2008.

LIU, A. et al. Born-Again Bit. A Framework for Migrating Electronic Literatures. In: The Electronic Literature Organization. 2005. Disponible en: $<$ http://eliterature.org/pad/bab.html>. Accedido junio 5, 2012.

LIU, A. The Laws of Cool. Knowledge Work and the Culture of Information. Chicago: University of Chicago Press, 2004.

MACHADO, A. Arte e mídia. Rio de Janeiro: Jorge Zahar Editor, 2007.

ROMANO SUED, S. La Diáspora de la Escritura. Una poética de la Traducción Poética. Córdoba: Alfa, 1995.

2007.

Consuelo de Lenguaje. Problemáticas de Traducción. Córdoba: Alción,

Poesía de experimentación: traducción del poema visual "Jetzt" de Max Bense al castellano. In: Alforja: revista de poesía. 2008. 
; VERA BARROS, T. (Eds.). Exposiciones. Metapoéticas de Literatura Argentina. Córdoba: El Emporio/epoKé, 2011.

SCHWENGER, P. Agrippa, or, The Apocalyptic Book. In: DERY, M. (Ed.). Flame wars: the discourse by cyberculture. Durham: Duke University Press, 1994. p. $61-70$.

WIEDIJK, F. Original Text of Gibson's «Agrippa». In: The Agrippa Files. 2011. Disponible en: <http://agrippa.english.ucsb.edu/post/documentssubcategories/the-disk-and-its-code/original-text-of-gibsons-agrippa-poemextracted-from-disk>. Accedido mayo 16, 2012.

Texto recebido em 05/11/2012. 